\title{
The effects of scopolamine hydrobromide on passive avoidance learning in rats
}

\author{
EVAN SUITS and ROBERT L. \\ ISAACSON, 2 The University of Michigan, \\ Ann Arbor, Mich. 48104
}

In a passive-avoidance test, rats received scopolamine either before or after the shock administration. They were tested twice afterwards-on the same day and again $48 \mathrm{~h}$ later. On the second test, the animals were first tested in a normal state and again after administration of scopolamine or saline. Scopolamine had no effect on passive avoidance behavior when tested on the first test on the day of shock, but it did impair performance on the second test day, $48 \mathrm{~h}$ later. Ss receiving scopolamine on this second test day which had also received the drug before were not impaired in the passive avoidance test.

Recently, a great deal of research has been directed towards determining the effects of anticholinergic drugs on behavior. For example, injection of such drugs has produced increases in activity (Tapp, 1965), perseveration of learned responses (Hearst, 1959), and reduction of spontaneous alternation (Douglas \& Isaacson, 1966).

Dramatic effects of these drugs have been found on avoidance learning behavior. Suits \& Isaacson (1968) showed that while scopolamine hydrobromide produces a deficit in one-way avoidance learning, the same treatment greatly enhances the learning of a two-way problem. Furthermore, Meyers (1964) and Bohdanecky \& Jarvik (1967) found that scopolamine injection disrupts passive avoidance behavior. Since these latter two studies involved one-trial passive avoidance paradigms and since perseveration of learned responses due to drug injection had already been demonstrated (Hearst, 1959), this study was undertaken to determine the effects of scopolamine hydrobromide in a passive avoidance problem where the animals had been more extensively pretrained in the response to be inhibited. Although the behavioral effects of scopolamine are unlikely to be explained on the basis of a general memory disorder, since both enhanced and impaired acquisition can occur under the drug, the present experiment was also undertaken to characterize differential effects of the drug given before or after the punishing shock in a passive avoidance situation. The animals were tested on the day of shock while under the influence of the drug and again two days later both with and without the drug. If performance was disrupted on the 48-h test while Ss were not under the drug, then an impairment in memory functions could be inferred. If the memory effect was found only in animals given the drug before the punishing shock one could infer a debility related to the incorporation of information. If a debility occurred in Ss given the drug after the shock one would conclude the memory disruption affected the "trace" of the punishing event. On the other hand, if no drugged Ss evidenced impaired performance in the second test, it would seem that the drug had not influenced memory, per se. Under this circumstance, if scopolamine reintroduced passive avoidance behavior, then it would appear that what was learned in the drugged state did not transfer to the nondrugged state and represents an instance of dissociated learning.

\section{APPARATUS}

The apparatus consisted of two, independently movable, grid-floored compartments each measuring $12 \times 20 \times 22 \mathrm{~cm}$ with guillotine type doors above $5-\mathrm{cm}$ high barriers at both ends. Each compartment had a partially masked Plexiglas top to allow observation of the $S$ and was illuminated from within by a $6-W$ bulb placed in the middle of one side, $2 \mathrm{~cm}$ from the ceiling. One compartment was painted inside with $1.2-\mathrm{cm}$ wide stripes alternating flat-black and gloss-white with the stripes oriented vertically, while the other compartment was painted with similar stripes oriented horizontally. Electric shock was provided by a Grason-Stadler shock generator, and latencies were timed with a stop clock. Room illumination was dim and indirect.

\section{SUBJECTS}

Subjects were 31 male albino rats approximately 80-100 days old and weighing $250-300 \mathrm{~g}$ at the beginning of the experiment. Ss were housed in individual cages where food was provided ad lib.

\section{PROCEDURE}

Prior to training, Ss were handled $15 \mathrm{~min}$ per day for 2 days. On the following 2 days they were allowed to explore the compartments of the training apparatus placed end to end with the intervening guillotine doors raised for $30 \mathrm{~min}$ each day.

Subjects were maintained on a $46-\mathrm{h}$ water deprivation schedule by allowing them access to water for $1 \mathrm{~h}$ beginning $1 \mathrm{~h}$ after training. Due to the deprivation period, and also to control for possible sensitization to the drug, Ss were run or handled only on alternate days.
On the first day of training, the two compartments were placed end to end and $S$ was placed in the right hand compartment with the light on. The tip of a water bottle was inserted through a small hole in the left hand door of the left hand compartment. After $30 \mathrm{sec}$ the intervening doors were raised, the light in the compartment containing $\mathrm{S}$ was extinguished, and the light in the other compartment lit. The trial was ended when S's hind feet crossed over the barrier. The doors were then lowered, the latency recorded, and $S$ allowed to drink from the water bottle for $10 \mathrm{sec}$. The position of the compartments was then reversed by moving the compartment containing $S$ directly backwards to the starting position while the former starting compartment was moved out and around into the goal position, thereby permitting $S$ to run in the same direction on every trial. After a 30-sec interval, the second trial was begun in the same manner as the first. If $S$ did not cross the barrier within $60 \mathrm{sec}$ on any trial, the doors were closed, the lights restored to their original condition before the start of the trial, and a maximum score of "60 sec" recorded.

Subjects were given 10 trials per day for 5 days. On the 6th day the animals were randomly divided into two experimental groups of 9 and $10 \mathrm{Ss}$ and two control groups of $6 \mathrm{Ss}$ each. The two experimental groups were designated "Before" and "After" (BE and AE) as were the control groups ( $B C$ and $A C)$. After four initial training trials on Day 6, animals of Groups $\mathrm{BE}$ and $\mathrm{BC}$ were injected i.p. with $1.0 \mathrm{mg} / \mathrm{kg}$ scopolamine hydrobromide from a solution of $0.4 \mathrm{mg} / \mathrm{ml}$ concentration. Groups $A C$ and $\mathrm{AE}$ were injected with equivalent volumes of isotonic saline. Ss were then returned to their home cages for $30 \mathrm{~min}$.

After $30 \mathrm{~min}$, Ss were returned to the apparatus and were given two "shock trials." On these trials Ss entered the goal box, the water was immediately withdrawn, and electrical shock applied to animals of the experimental groups. Ss in Groups BE and $\mathrm{AE}$ received five $0.8-\mathrm{mA}$ shocks of $0.5-\mathrm{sec}$ duration through the grid floor, while $S s$ in Groups BC and AC received no shock. All Ss were then removed, injected with saline or scopolamine and again returned to their home cages. At this time, animals of Groups $\mathrm{AE}$ and $\mathrm{AC}$ received scopolamine and Groups $B E$ and $B C$ received saline. After $30 \mathrm{~min}$, Ss were returned to the apparatus for eight more test trials identical in format to the training trials. 
Table 1

Medians, Means, and Standard Deviations for Test Trials

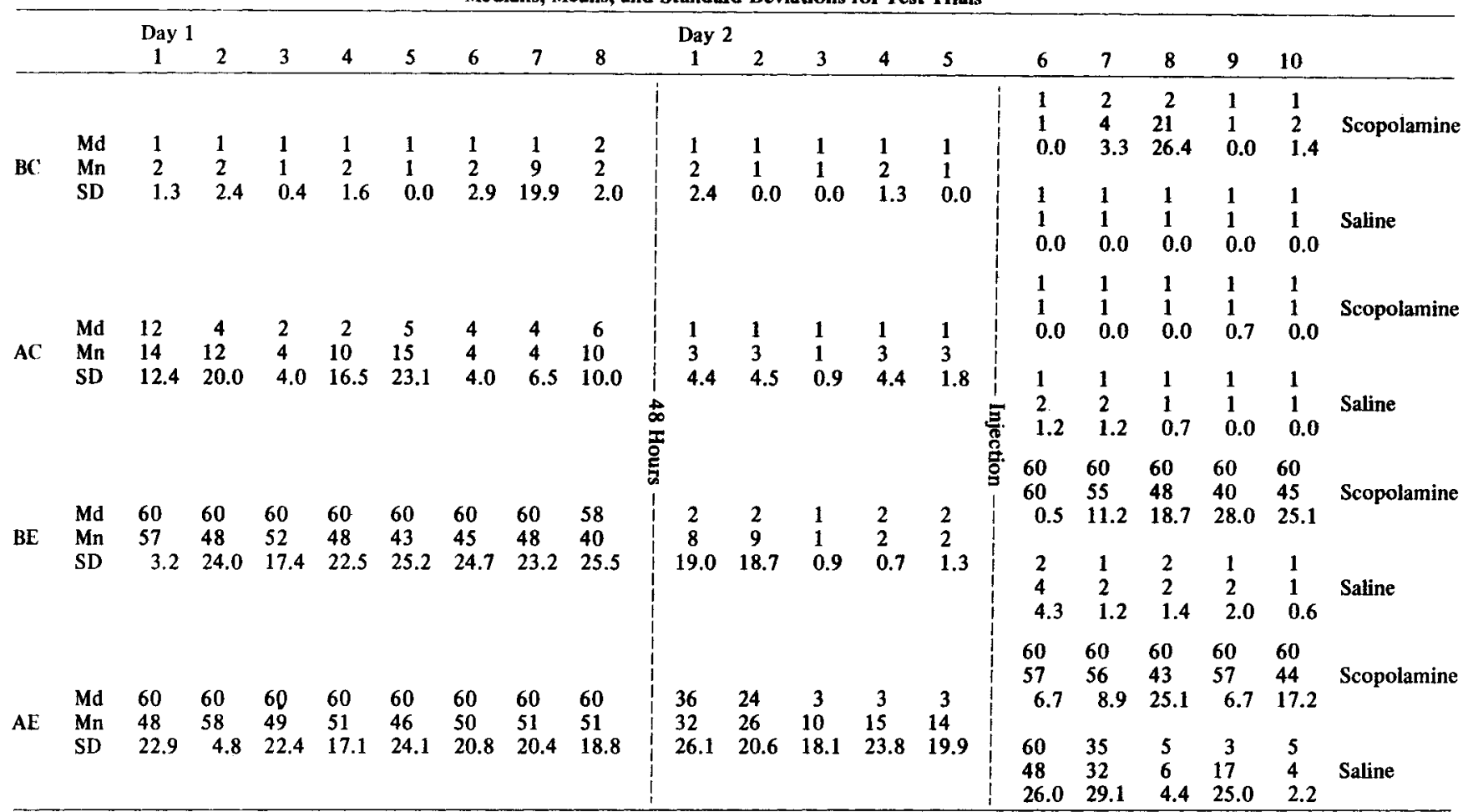

Forty-eight hours later, all Ss were given five more test trials and then removed and injected with saline or scopolamine. Onehalf of the Ss in each of the four previously used groups received scopolamine, while the other half received saline. After $30 \mathrm{~min}$ in their home cages, all Ss were returned to the apparatus and given another five test trials. RESULTS

Since the number of Ss in any group was not extremely large and since trials were arbitrarily terminated after $60 \mathrm{sec}$ if a response had not been made, we believe that an adequate description of behavior required both the means and medians of the group. Consequently, these are provided in Table 1, as are the standard deviations.

The data on test trials for Test Day 1 , on which the shock was administered show the control groups to be unaffected by the injections whereas the two experimental groups exhibit maximum latencies on all eight postshock and injection trials. On Test Day 2, $48 \mathrm{~h}$ later, the control groups approach the goal box with the same low latencies exhibited in prior training and are unaffected by the drug injections, alone. In the experimental groups, Group BE shows significantly $(p=.05$, Fisher's Exact Test; Finney et al, 1963) lower latencies on the first two trials than Group AE. This result indicates that the shocks had less effect on the animals given the drug before the shock than the group receiving the drug after the shock.
Following the injection on the second test day, Ss of both experimental groups which received scopolamine returned to maximum latency passive avoidance responses. The $S s$ of Group BE which received saline remained at low latency responding. Ss of Group $\mathrm{AE}$ receiving saline showed some tendency toward passive avoidance on the subsequent two trials but then returned to rapid responding. Therefore, Ss that received shock while under the influence of the drug seemed to be most affected by the shock when under the influence of the drug. Animals that received the drug after the shock similarly showed significant passive avoidance under the influence of the drug. DISCUSSION

The data of this experiment would appear to be in conflict with previous work. For example, the nearly perfect passive avoidance of Ss in both experimental groups on the eight trials following the shock seems contradictory to the reports of Meyers (1964) and Bohdanecky \& Jarvik (1967) who both reported failure of drugged Ss to inhibit punished responses even when tested immediately after the shock. However, these Es gave Ss little or no training before the application of the punishing shock. It would appear from our data that such training does not increase the likelihood of responding following punishing electrical shock. This is surprising in light of the work of Hearst (1959) from which it would be expected that such a well learned response would not be so completely suppressed in the scopolamine animals. The response disinhibition effect reported by Hearst and the reported absence of passive avoidance behavior in other studies combine to make the data reported here unexpected.

Animals that received the shock while under the influence of scopolamine (Group BE) evidenced a loss of memory for the experience except when tested again while under the influence of the drug (Test Day 2). Animals that received the drug after the shock (Group AE) showed some retention of the experience on the second test day and when again injected with the drug showed full retention of the passive avoidance response. The possibility that the drug itself would produce the extended latencies can be discounted by the control group performances. The results of Group BE before the second injection of scopolamine on the second test day suggest that the Ss' difficulty might be attributed to an impairment in the incorporation of information in the drugged state. However, since the second injection of the drug on this second test day immediately reestablished the full-blown passive avoidance behavior it is likely that the effects of the punishing shock had been adequately registered. This information, while registered and stored, was evidently either of little use or unavailable in the nondrugged state.

Overton (1966) has suggested that Ss may associate the peripheral cues of the drugged 
state, such as dryness of the mouth, etc., with the shock, and subsequent injections could then restore that stimulus complex associated with the punishment. This explanation could easily be applied to the animals of Group BE since the drug effects were well established when shock was applied but less easily to animals of Group AE which received the drug after the shocks. Perhaps one could assume that, although AE Ss received the drug on Test Day 1 after the shock, the autonomic reactions to the shock lasted long enough to be associated with the peripheral effects of the drug. Weak as this explanation is, it could be tested in the future by the administration, on Test Day 2, of methyl -scopolamine which is thought to have the same peripheral effects as scopolaminehydrobromide but does not pass the blood-brain barrier and therefore should have fewer central effects. If memory of the shock is dependent on the peripheral cues then the two drugs should be of equal effectiveness at this point in time. This explanation, however, does not account for the effects of the drug found in other types of tasks. In active avoidance learning tasks (Suits \& Isaacson, 1968) injection of the drug produces significant increments or decrements in performance even though the $S$ is always trained in the drugged state. Tapp (1965) found increased activity in drugged Ss while Douglas \& Isaacson (1966) found spontaneous alternation reduced to near chance level in rats under the influence of scopolamine. These varied results cannot be readily attributed to dissociation effects alone and further explanations must be sought.

\section{REFERENCES}

BOHDANECKY, Z \& JARVIK, M. E Impairment of one-trial passive avoidance learning in mice by scopolamine, scopolamine methylbromide, and physostigmine. International Journal of Neuropharmacology, 1967, 6 217-222.

DOUGLAS, R. J., \& ISAACSON, R. L Spontaneous alternation and scopolamine. Psychonomic Science, 1966, 4, 283-284.

FINNEY, D. J., LATSCHA, R., BENNETT, B. M. \& HSU, P. Tables for testing significance in a $2 \times 2$ contingency table. London: Cambridge University Press, 1963.

HEARST, E. Effects of scopolamine on discrim inated responding in the rat. International Journal of Pharmacology \& Experimenta Therapeutics, 1959, 126, 349-358.

MEYERS, B. Some effects of scopolamine on passive avoidance response in rats. Psychopharmacologia (Berlin), 1965, 8, 11 1-119.

OVERTON, D. A. State dependent or "dissociated" learning produced with pentobarbitol Journal of Comparative \& Physiological Psychology, 1964, 57, 3-12.

SUITS, E., \& ISAACSON, R. L. The effects of scopolamine hydrobromide on one-way and two-way avoidance learning in rats. International Journal of Neuropharmacology, 1968, 7, 1-6.

TAPP, J. T. Cholinergic mechanisms in operant responding. Journal of Comparative \& Phy siological Psy chology, 1965, 59, 469-472. NOTES

1. This investigation was supported in part by a grant from the National Institute of Mental Health (NIH MH-112-8502) to R. L. Isaacson.

2. Both authors are now at the Department of Psy chology, The University of F lorida, Gainesville, Florida 32601.

between the magnitude of $\mathrm{R}_{\mathrm{F}}$ and the magnitude of the fractional anticipatory goal response $\left(r_{g}\right)$. Several studies have demonstrated that factors assumed to determine $r_{g}$ are related to the magnitude of the FE. Peckham \& Amsel (1967), for example, using a within-Ss design, have shown that the size of the FE varies with the magnitude of reward given in the first goal box in a double-alley situation.

The relationship between another variable assumed to determine the strength of $r_{g}$, number of conditioning trials $\left(\mathrm{N}_{G}\right)$ (Spence, 1956), and the magnitude of the FE has received little experimental attention. Marzocco (1951) using a modified Skinner box in which measures of force exerted to depress the bar were taken, found that the FE, defined as differences in force exerted on presses prior to nonreward and force exerted during nonreward, tended to be greater in groups given 24 or 72 rewarded presses than in an 8-reward group. No double-alley studies, however, have attempted to confirm Marzocco's results. The purpose of the present study was to investigate the effect of $\mathrm{N}_{\mathrm{G}}$ on the magnitude of the $\mathrm{FE}$ in the double-alley situation.

\section{METHOD}

The Ss were 42 experimentally naive male rats, 90-100 days old at the start of the habituation period, obtained from the Holtzman Company.

The apparatus consisted of two straight alleys, $4 \mathrm{in}$. high and $3 \frac{1}{2}$ in. wide, placed end to end and illuminated by a moderately dim diffused light source centered above the alleys. All surfaces of the alleys visible to $S$ were painted flat black. Alley 1 consisted of a start box, 9 in. long, separated by a metal dropping door from the 48-in. long alley. A 12-in. long goal box (GB1) served as the start box for Alley 2 and was separated from Alley 1 by a metal sliding door to prevent

\section{Magnitude of the frustration effect and number of training trials}

\begin{abstract}
DELPHINE YELEN, Washburn University, Topeka, Kans. 66621
\end{abstract}

Groups of 14 rats were given either 12 , 36 , or 60 continuously reinforced trials in a double-alley situation and then shifted to a $50 \%$ partial reinforcement schedule in the first goal box for 30 test trials to determine the effect of number of reinforced trials on the magnitude of the frustration effect $(F E)$. Results indicated a significant $F E$ in all three groups, with the FE in the 60-trial group larger than in the 36-or 12-trial groups, and no difference in the size of the FE for the latter two groups.
The theory of frustrative nonreward proposed by Amsel (1958, 1962) and Spence (1960) assumes that nonreinforcement of a previously reinforced response produces a primary frustration response $\left(R_{F}\right)$ which contributes to the drive level of the organism. In the double-alley apparatus typically used to demonstrate the presence of $R_{F}$ (e.g., Amsel \& Roussel, 1952), omission of reward in the first goal box on some trials after a history of previously rewarded trials produces the frustration effect (FE), or faster running in Alley 2 following nonreward than following reward.

The theory of frustrative nonreward also assumes that there is a positive relationship retracing and from Alley 2 by a metal dropping door. Alley 2 was 60 in. long with a 12-in. long goal box (GB2). GB2 was separated from Alley 2 by a metal sliding door to prevent retracing. A small metal food cup was set in flush with the floor in GB1 immediately in front of the metal dropping door. A glass food cup set in to a painted wooden form was placed at the end of GB2.

When the start door to Alley 2 was dropped a microswitch was triggered starting a Standard Electric clock. Interruption of a light beam 12 in. from the start door stopped this clock and started a second. Interruption of a light beam 36 in. farther down Alley 2 stopped the second clock. Start time, then, was measured over a distance of $12 \mathrm{in.,} \mathrm{running} \mathrm{time} \mathrm{over} \mathrm{a}$ distance of $36 \mathrm{in.}$ All times were converted to reciprocals. 